\title{
CONTROLADORIA: UMA VISÃO ACERCA DA INDÚSTRIA TÊXTIL DA REGIÃO DO BRÁS NO MUNICÍPIO DE SÃO PAULO
}

\section{CONTROLLER: A VIEW ABOUT THE TEXTILE INDUSTRY OF THE BRÁS REGION IN THE CITY OF SÃO PAULO}

Recebido: 05/09/2016 - Aprovado: 14/10/2016 - Publicado: 10/12/2016

Processo de Avaliação: Double Blind Review

\author{
Juliano Augusto Orsi De Araujo ${ }^{1}$ \\ Mestre em Ciências contábeis \\ Fundação Escola De Comércio Álvares Penteado- FECAP \\ julianoorsi@usp.br \\ Wariston Soares Ferreira \\ Especialista em controladoria estratégica \\ Fundação Escola De Comércio Álvares Penteado- FECAP \\ wariston_contabeis@yahoo.com.br
}

\section{RESUMO}

Em um ambiente de grande competitividade, com concorrência interna e externa, o setor têxtil brasileiro enfrenta dificuldades de manutenção das atividades e perspectiva de crescimento comprometida. Este cenário é potencializado quando se volta o olhar para as pequenas e médias empresas do setor. Neste sentido, a empresa que apresenta alguma preocupação com a estruturação de sua gestão, com conceitos apresentados pela controladoria, consegue algum destaque no setor mantêm-se competitiva. Deste modo, a presente pesquisa buscou identificar a percepção dos gestores do setor sobre a controladoria e se ela existe, ainda que informalmente, nas empresas pesquisadas. Foram entrevistados 41 gestores de confecções estabelecidas na região do Brás, no município de São Paulo. O questionário foi fechado e as respostas foram coletadas manualmente, in loco, no período de 28 de abril a 06 de maio de 2014. Como principais achados, destacam-se a percepção da importância do controle na

\footnotetext{
${ }^{1}$ Autor para correspondência:, Fundação Escola De Comércio Álvares Penteado- FECAP, Av Liberdade, 532, Liberdade, São Paulo, SP, Brasil, 01502-001
}

REMIPE- Revista de Micro e Pequenas Empresas e Empreendedorismo da Fatec Osasco V. 2, `o2, jul.-dez. 2016. 
organização, a adoção de controles manuais ou em fichas e algum interesse em implantação de software integrado para auxiliar na gestão.

Palavras-chave: Controladoria; Planejamento Estratégico; Confecção.

\section{ABSTRACT}

In a highly competitive environment with internal and external competition, the Brazilian textile sector faces difficulties to maintain its activities and has the growth prospects affected. This scenario is strengthened when evaluating the small and medium enterprises. In this way, the company that has some concern with the structure of its management, through concepts presented by the comptroller, achieves some prominence in the industry and remain competitive. Thus, the present study sought to identify the perceptions of industry managers about the Controllership and verify if this area is part of the business, albeit informally, in the companies surveyed. There were 41 managers interviewed from clothing companies established in the Brás region, in São Paulo city. The questionnaire was closed and the responses were collected manually, on-site, from April 28 to May 6, 2014. The main findings of the study shows that there is awareness about the importance of Controllership in the organization, the companies use some type of control, even though by paper or spreadsheets, but there is concern in develop and implement software to improve the management.

Keywords: Controllership; Strategic Planning; Clothing Industry.

\section{INTRODUÇÃO}

Nos últimos anos, as indústrias de confecção do Brasil têm crescido significantemente, tal fato, consequentemente, tem beneficiado a economia brasileira e contribuído na geração de emprego e renda para a população. Segundo o Ministério de Desenvolvimento, Indústria e Comércio Exterior (MIDC, 2010), o setor têxtil e de confecção é relevante para a economia brasileira, uma vez que se trata do segundo maior gerador do

REMIPE- Revista de Micro e Pequenas Empresas e Empreendedorismo da Fatec Osasco V. 2, `o2, jul.-dez. 2016. 
primeiro emprego, além de ser o segundo maior empregador na indústria de transformação e representar 3,5\% do PIB Brasileiro. Diante desse crescimento econômico, a Federação das Indústrias do Estado de São Paulo (FIESP, 2013), em 2013, realizou um estudo referente à indústria têxtil e de confecção onde constatou que este seguimento representa uma projeção de crescimento de $3 \%$ em 2014.

Em virtude desse crescimento industrial, as empresas estão buscando uma melhor qualidade de informações, de maneira que sejam mais eficientes e estejam em conformidade com a sua realidade econômica. Catelli (2001) informa que o resultado econômico é o melhor indicador da eficácia empresarial. Dessa forma, com o intuito de aperfeiçoar esses resultados econômicos, a controladoria tem como papel auxiliar no processo de controle e gestão das empresas. Segundo Padoveze (2009), a Controladoria é a unidade administrativa que contribui para a utilização de todo o conjunto da Ciência Contábil dentro da empresa.

Devido aos mecanismos de controle, esta unidade da administração funciona de forma interligada com todos os setores dentro da empresa e também tem a função de apoiar a gestão de negócios na tomada de decisão. Conforme Nascimento e Reginato (2007), a Controladoria também tem a função de promover a eficácia das decisões e monitorar a execução dos objetivos estabelecidos, já que a autenticidade de seus dados serve de referência na tomada de decisão de curto ou longo prazo. Padoveze (2009) ressaltou que à controladoria cabe a responsabilidade de implantar, desenvolver, aplicar e coordenar todas as ferramentas da Ciência Contábil dentro da empresa.

A busca de informações sólidas e precisas é tudo o que a empresa precisa para definir o seu planejamento futuro. Contudo, Roehl, Janice e Bragg (2004) afirmaram que o principal fundamento da controladoria é de suprir as necessidades dos gestores. O crescimento da empresa é baseado em uma gestão econômica em que o departamento da controladoria funciona no auxílio da gestão.

Neste sentido, este artigo tem o objetivo de identificar a percepção dos gestores sobre a controladoria, bem como analisar as informações colhidas durante a pesquisa, na busca da identificação dos pontos fortes e fracos na visão de diferentes gestores.

REMIPE- Revista de Micro e Pequenas Empresas e Empreendedorismo da Fatec Osasco V. 2, №2, jul.-dez. 2016. 
Assim, o resultado a ser apresentado na pesquisa visa enriquecer as práticas de controladoria em relação às funções do gestor de micro e pequenas empresas no seguimento de confecção. A contribuição da pesquisa se dá em dois aspectos: profissional e acadêmico. Profissional, devido à exigência do mercado na busca de gestores empreendedores que saibam coletar dados para o planejamento, execução e controle das atividades das empresas. Acadêmico, pois os fatos apresentados na pesquisa contribuem no enriquecimento da controladoria, que têm por finalidade orientar os processos administrativos de empresas.

O estudo apresentado neste artigo é relevante ao meio acadêmico e profissional por ser uma pesquisa em que se utilizou o conceito de controladoria para verificar o resultado da gestão desta entre diferentes profissionais da área de confecção. Em âmbito profissional, o artigo apresenta algumas ferramentas de controladoria utilizadas habitualmente no setor de confecção, além de contribuir para comparar a expectativa de desenvolvimento econômico do gestor em relação ao mercado de trabalho.

\section{REFERENCIAL TEÓRICO}

Ao longo do referencial teórico, serão apresentados conceitos acerca da controladoria e um panorama sobre o setor têxtil, com foco para a região do Brás, no município de São Paulo. Em função da particularidade da amostra, faz-se necessário também identificar as características de micro e pequenas empresas, predominantes naquela região.

\subsection{Controladoria}

Segundo Garcia (2010), a controladoria teve início nos Estados Unidos em meados do século XX, tendo como principal objetivo auxiliar no controle das empresas e nos seus receptivos negócios. De acordo com Casagrande e Pinto (2011), na era da Revolução Industrial, as grandes empresas começaram a se fundir, fazendo com que surgisse a necessidade de controle dos seus respectivos negócios. Schmidt (2002), comenta que as grandes companhias fundidas eram gerenciadas por departamentos que prestavam contas aos seus respectivos gerentes, sendo assim, a controladoria era utilizada como forma de controle

REMIPE- Revista de Micro e Pequenas Empresas e Empreendedorismo da Fatec Osasco V. 2, №2, jul.-dez. 2016. 
de dados e para auxiliar o gestor empresarial no planejamento e na tomada de decisões a respeito dos negócios da empresa.

Roehl, Anderson e Bragg (1996) apud Nascimento (2011, p.02) afirmam que:

A controladoria atua compreendendo as operações globais da empresa, promovendo informações e tendo o poder de comunicação destas aos gestores e áreas, disponibilizando projeções baseadas em sua obtenção e análise, fornecendo-as, por fim, em tempo hábil para tomada de decisão.

Beuren, Schlindwein e Pasqual (2007) também concordam com o pensamento de que a controladoria representa a evolução da contabilidade no papel de organizar a demanda de informações dos administradores. Em virtude desse papel, Cavalcanti (2001) apud Beuren, Schlindwein e Pasqual (2007) considera que a controladoria apresenta quatro funções principais: planejamento, organização, direção e avaliação. Planejamento da disponibilidade de recursos, organização na busca de ferramentas tecnológicas para eficiência de dados, direção para concretizar as diretrizes da empresa e avaliação para mensurar os resultados do período.

\subsection{Etapas de Controladoria}

Para a eficácia da controladoria Wilson, Roehl-Anderson e Bragg (2000), apud Scarpin (2006), apresentam cinco etapas que especificam melhor o trabalho que pode ser realizado pelo gestor de micro e pequenas empresas.

REMIPE- Revista de Micro e Pequenas Empresas e Empreendedorismo da Fatec Osasco V. 2, `o2, jul.-dez. 2016. 
Quadro 1 - Etapas da controladoria

\begin{tabular}{|c|c|c|c|}
\hline \multicolumn{4}{|c|}{ Etapas da Controladoria } \\
\hline Planejamento & \multicolumn{2}{|l|}{ Controle } & Relatórios \\
\hline $\begin{array}{l}\text { Estabelecimento } \\
\text { manutenção de um plano } \\
\text { integrado de operações de } \\
\text { curto e longo prazo, } \\
\text { consistente com as metas e } \\
\text { objetivos da companhia, } \\
\text { comunicado a todos os níveis } \\
\text { da gerência, sendo analisado } \\
\text { e revisado quando necessário } \\
\text { e utilizando de sistemas e } \\
\text { processos instados } \\
\text { corretamente. }\end{array}$ & \multicolumn{2}{|c|}{$\begin{array}{l}\text { Desenvolvimento e revisão } \\
\text { de padrões para avaliação } \\
\text { do desempenho e para } \\
\text { prover linhas gerais e } \\
\text { suporte aos membros da } \\
\text { gerência, a fim de assegurar } \\
\text { a comparação dos resultados } \\
\text { realizados com estes } \\
\text { padrões, considerando } \\
\text { informações financeiras e } \\
\text { não financeiras. }\end{array}$} & $\begin{array}{l}\text { Preparação, análise e } \\
\text { interpretação dos resultados } \\
\text { financeiros para utilização } \\
\text { da gerência no processo } \\
\text { decisório, proporcionando } \\
\text { análise das informações } \\
\text { com referência aos objetivos } \\
\text { da companhia. Preparação } \\
\text { de relatórios para } \\
\text { autoridades reguladoras, } \\
\text { acionistas, instituições } \\
\text { financeiras, clientes e para o } \\
\text { público geral. }\end{array}$ \\
\hline \multicolumn{2}{|l|}{ Contabilidade } & \multicolumn{2}{|c|}{ Outras responsabilidades } \\
\hline \multicolumn{2}{|c|}{$\begin{array}{l}\text { Desenho, estabelecimento e manutenção da } \\
\text { contabilidade geral e custos para toda } \\
\text { companhia, registrando adequadamente } \\
\text { todas as transações nos livros, de acordo } \\
\text { com os princípios contábeis e controles } \\
\text { internos, com flexibilidade suficiente para } \\
\text { prover informações essenciais requeridas } \\
\text { pela urgência para planejar e controlar } \\
\text { adequadamente os negócios da companhia. }\end{array}$} & \multicolumn{2}{|c|}{$\begin{array}{l}\text { Relacionamento com auditores externos, } \\
\text { investidores, órgãos reguladores, } \\
\text { responsável pelas áreas tributária, segurança } \\
\text { da informação, dentre outros. }\end{array}$} \\
\hline
\end{tabular}

Fonte. Wilson, Roehl-Anderson e Bragg (2000), apud Scarpin (2006, p.74)

Borinelli (2006), argumenta que as etapas das atividades da controladoria devem estar de acordo com a realidade econômica da empresa. O controlador utiliza-se do processo de gestão para o gerenciamento de suas funções. O acompanhamento das etapas auxilia na mensuração de resultados conforme a estrutura da companhia.

REMIPE- Revista de Micro e Pequenas Empresas e Empreendedorismo da Fatec Osasco V. 2, №2, jul.-dez. 2016. 
De acordo com Garcia (2007), no mercado de trabalho atual, são funções exigidas pelo departamento de controladoria: a elaboração de planejamento financeiro; confecção de relatórios gerenciais visando dar suporte para tomadas de decisão à diretoria; revisão e implementação de processos de controle; coordenação de planejamentos estratégicos; construção de cenários econômicos; análise competitiva e análise de viabilidade econômica de projeções de investimentos

\begin{tabular}{|c|c|}
\hline $\begin{array}{l}\text { Processo de } \\
\text { Gestão }\end{array}$ & Funções e atividades da controladoria \\
\hline \multirow{4}{*}{ Planejamento } & $\begin{array}{l}\text { Participar das definições estratégicas, tomando decisões em conjunto } \\
\text { com os demais gestores, sendo coordenadora do processo. }\end{array}$ \\
\hline & Coordenar o processo de construção do plano em nível operacional. \\
\hline & $\begin{array}{l}\text { Assessorar as diversas unidades com informações de caráter } \\
\text { operacional, econômico, financeiro e contábil. }\end{array}$ \\
\hline & $\begin{array}{l}\text { Consolidar os diversos planos das unidades em um planejamento global } \\
\text { integrado e otimizado. }\end{array}$ \\
\hline \multirow{5}{*}{ Orçamento } & Coordenar o processo de construção do orçamento. \\
\hline & $\begin{array}{l}\text { Determinar, em conjunto com a administração e demais áreas, as } \\
\text { premissas e diretrizes orçamentárias. }\end{array}$ \\
\hline & Assessorar as demais áreas na elaboração dos seus orçamentos. \\
\hline & Consolidar os orçamentos das áreas em um orçamento global. \\
\hline & $\begin{array}{l}\text { Avaliar os orçamentos das áreas, a fim de verificar se atendem as } \\
\text { definições dos planos estratégicos, tático e operacional. }\end{array}$ \\
\hline \multirow{4}{*}{ Execução } & Auxiliar as áreas na aplicação dos recursos planejados. \\
\hline & Dar suporte às áreas na implementação dos projetos. \\
\hline & $\begin{array}{l}\text { Coordenar os esforços dos gestores das diversas áreas na consecução } \\
\text { dos seus respectivos objetivos. }\end{array}$ \\
\hline & Fornecedor apoio informacional sobre o andamento dos planos. \\
\hline \multirow{6}{*}{ Controle } & $\begin{array}{l}\text { Gerar informações que contemplem eventos planejados e realizados, } \\
\text { para verificar a aderência entre os planos e o real, inclusive com } \\
\text { relatórios. }\end{array}$ \\
\hline & Interagir com as demais áreas para identificar as causas dos desvios. \\
\hline & Exercer, efetivamente, o controle. \\
\hline & Garantir a eficácia do sistema de controle. \\
\hline & Revisar, periodicamente, o sistema de controle. \\
\hline & Coordenar o processo de controle. \\
\hline
\end{tabular}

Fonte: Borinelli (2006) apud Cruz (2009, p.52).

REMIPE- Revista de Micro e Pequenas Empresas e Empreendedorismo da Fatec Osasco V. 2, N`2, jul.-dez. 2016. 


\subsection{Micros e Pequenas Empresas}

Essas funções podem ser organizadas em quatro processos: planejamento, orçamento, execução e controle.

A função da controladoria não se limita apenas às grandes empresas, mas também às micro e pequenas. Segundo o artigo $3^{\circ}$ da LC. 123/06 define-se com microempresa ou empresa de pequeno porte aquela que no seu ano calendário possui receita bruta igual ou inferior a $\mathrm{R} \$ 360.000,00$ (trezentos e sessenta mil reais), ou, no caso de empresas de pequeno porte, aufira, em cada ano-calendário, receita bruta superior a $\mathrm{R} \$ 360.000,00$ (trezentos e sessenta mil reais) e igual ou inferior a $\mathrm{R} \$ 3.600 .000,00$ (três milhões e seiscentos mil reais). (BRASIL, 2006).

De acordo com o Serviço Brasileiro de Apoio às Micro e Pequenas Empresas SEBRAE (2013), em 2009 existiam 438.513 empresas desse porte no território nacional. As empresas de pequeno porte - EPP, estão concentradas essencialmente no eixo Sul-Sudeste, sendo o estado de São Paulo o de maior relevância, com 132.501 pequenas empresas, cerca de $30 \%$ do total. Em seguida aparecem Minas Gerais (45.342) e Rio Grande do Sul (39.893), o Amapá é o estado com menor número de empresas de pequeno porte, sendo 451 no total. Segundo o Banco Nacional do Desenvolvimento - BNDES (2009), as EPP's geram 17,3\% dos empregos nas indústrias brasileiras, o que reflete a importância das empresas deste porte no desenvolvimento da economia nacional.

\subsection{Setor de Confecção}

De acordo com Monteiro Filho e Santos (2002), as indústrias de confecção internacionais utilizam-se, de forma estratégica, como referência de mercado o modelo econômico baseado nos produtores com marcas, comerciantes com marcas e rede de varejo com marcas, visando conquistar o mercado mundial.

REMIPE- Revista de Micro e Pequenas Empresas e Empreendedorismo da Fatec Osasco V. 2, `o2, jul.-dez. 2016. 
Quadro 3 - Modelo de organização do ramo de confecção na ordem mundial

\begin{tabular}{|c|c|c|c|}
\hline \multicolumn{4}{|c|}{ Modelo de organização do ramo de confecção na ordem mundial } \\
\hline \multirow{4}{*}{ 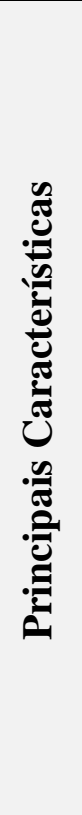 } & $\begin{array}{c}\text { Produtores com } \\
\text { marca }\end{array}$ & $\begin{array}{c}\text { Comercializadores com } \\
\text { marca }\end{array}$ & Varejistas com marca \\
\hline & $\begin{array}{l}\text { Empresas } \\
\text { dedicadas } \\
\text { produção } \\
\text { vestuário }\end{array}$ & $\begin{array}{l}\text { Comercializadores que } \\
\text { tem o foco em design e } \\
\text { comercialização }\end{array}$ & $\begin{array}{l}\text { Empresas de varejo e } \\
\text { grandes magazines }\end{array}$ \\
\hline & $\begin{array}{lr}\text { Possuem } & \text { sistema } \\
\text { integrado } & \text { de } \\
\text { produção } & \text { na } \\
\text { fabricação } & \text { dos } \\
\text { produtos } & \\
\end{array}$ & $\begin{array}{l}\text { Não possuem ou se } \\
\text { envolvem com } \\
\text { atividades produtivas }\end{array}$ & $\begin{array}{l}\text { Sistemas de padronização de } \\
\text { produção em alta escala }\end{array}$ \\
\hline & $\begin{array}{lr}\text { Estuda } & \mathrm{o} \\
\text { entendimento } & \mathrm{e} \\
\text { evolução } & \text { das } \\
\text { tendências } & \mathrm{e} \\
\text { gostos } & \text { dos } \\
\text { consumidores } & \end{array}$ & $\begin{array}{l}\text { Define a marca e a } \\
\text { especificação do produto }\end{array}$ & $\begin{array}{l}\text { Maiores revendedores são os } \\
\text { hipermercados } \\
\text { supermercados com grande } \\
\text { volume e preço baixo }\end{array}$ \\
\hline
\end{tabular}

Fonte: Monteiro Filho e Santos (2002).

Segundo Costa e Rocha (2009), os principais países líderes na produção têxtil são: A China (incluindo Hong Kong) como a principal produtora mundial, respondendo por 43,4\% da produção mundial, em seguida os Estados Unidos (7,9\%), Índia (7,1\%), Paquistão $(6,1 \%)$, Taiwan $(2,7 \%)$ e demais países com $(32,8 \%)$. 
Quadro 4 - Polos regionais de produção têxtil e confecções

\begin{tabular}{|c|l|l|}
\hline \multicolumn{3}{|c|}{ Principais polos regionais de produção têxtil e confecção } \\
\hline \multicolumn{1}{|c|}{ Estados } & \multicolumn{1}{|c|}{ Especializaçóes } \\
\hline São Paulo & $\begin{array}{l}\text { São Paulo (bairro } \\
\text { do Brás e Bom } \\
\text { Retiro) } \\
\text { Americana }\end{array}$ & $\begin{array}{l}\text { Destaca-se como o mais importante centro } \\
\text { produtor, além de ser o centro intelectual e } \\
\text { financeiro da indústria, pois concentra os principais } \\
\text { ativos intangíveis (moda marketing etc.) e } \\
\text { Americana que apresenta elevado desenvolvimento } \\
\text { tecnológico e é especializada na produção de } \\
\text { tecidos artificiais e sintéticos. }\end{array}$ \\
\hline Rio de Janeiro & $\begin{array}{l}\text { Nova Friburgo } \\
\text { Petrópolis }\end{array}$ & $\begin{array}{l}\text { Principal polo produtor de lingerie do país e } \\
\text { Petrópolis, especializada em malharia e roupas de } \\
\text { inverno. }\end{array}$ \\
\hline Santa Catarina & $\begin{array}{l}\text { Blumenau (Vale } \\
\text { do Itajaí) }\end{array}$ & $\begin{array}{l}\text { É um dos polos têxteis mais avançados da América } \\
\text { Latina e o centro brasileiro com maior inserção no } \\
\text { mercado internacional, sendo o principal } \\
\text { exportador nacional de artigos de malha e linha. }\end{array}$ \\
\hline Ceará & Fortaleza & $\begin{array}{l}\text { Vale destacar a forte presença de empresas } \\
\text { verticalmente integradas, especialmente no ramo de } \\
\text { tecidos denim (brim) e em fios de algodão. }\end{array}$ \\
\hline
\end{tabular}

Fonte: Costa e Rocha (2009, p. 174).

De acordo com Costa e Rocha (2009, p. 174) os principais estados brasileiros que são polos regionais de produção têxtil e confecção são os apresentados no quadro 4.

\section{METODOLOGIA}

Esta seção destina-se a fundamentação metodológica da pesquisa, sendo esta distribuída em duas seções: Conceito de pesquisa e a Coleta e tratamento dos dados.

A pesquisa tem natureza descritiva, pois buscou evidenciar fenômenos em determinada amostra de população (SILVA; MENEZES, 2005), e possui abordagem qualitativa, pois trata variáveis fenômenos. A fonte da pesquisa é primária, considerando que se utiliza de informações que buscam evidenciar as características da controladoria como fator de gerenciamento empresarial (SIQUEIRA; SOLTELINHO, 2001). O método de pesquisa e coleta de dados se deu por meio de questionários e entrevistas com empresários e gestores ligados à área de confecção

REMIPE- Revista de Micro e Pequenas Empresas e Empreendedorismo da Fatec Osasco V. 2, `2, jul.-dez. 2016. 
Os dados foram coletados no período do dia 28 de abril a 06 de maio de 2014, distribuídos diretamente por meio de questionário com treze perguntas fechadas. As informações coletadas foram tabuladas utilizando o programa de computador Excel. Após a tabulação, foi aplicada estatística descritiva para buscar a essência da reposta com cruzamentos de dados.

O questionário foi aplicado na região do Brás em São Paulo, por ser um dos maiores polos comercias do Brasil no ramo de tecidos e roupas, e também por esta região ser conhecida como fonte de renda para suprir a economia confeccionista. A pesquisa foi aplicada em 50 empresas de confecção na região e obteve $82 \%$ de retorno, os $18 \%$ que não responderam alegaram falta de tempo para fazê-lo, devido ao acúmulo de tarefas do dia a dia.

\section{DISCUSSÃO DOS RESULTADOS}

Inicialmente, buscou-se traçar um perfil dos respondentes. Dos gerentes que responderam $29,27 \%$ tinham entre 20 a 30 anos, $31,71 \%$ de 30 a 40 anos, 24,39\% de 40 a 50 anos e 14,63\% possuíam idade acima de 50 anos. Destes gerentes, 17,07\% possuem o ensino fundamental, 46,34\% o ensino médio, $19,51 \%$ o ensino técnico, 12,20\% possuem o curso superior e 4,88\% não declararam seu grau de instrução.

Ao indagar sobre o tempo de experiência na área, 26,83\% tinham 5 anos de experiência, $31,71 \%$ de 5 a 10 anos, 29,27\% de 10 a 20 anos e acima de 20 anos eram 12,20\%. Em virtude do crescimento do setor, a pesquisa permitiu identificar que os profissionais que trabalham há mais tempo no segmento são aqueles que possuem formação até o ensino médio e que apenas a minoria busca uma melhor qualificação profissional.

Embora São Paulo seja um marco do polo têxtil e confecção no Brasil, apenas $14,63 \%$ participam de 1 a 2 vezes por ano em eventos do seguimento, 36,59\% participam no mínimo três vezes ao ano, e 34,15\% nunca participam deste tipo de eventos. Os principais recursos de reciclagem e atualização de conhecimento em confecção são os cursos presenciais com $26,83 \%$, em segundo, com $19,51 \%$ são os cursos online, $14,63 \%$ disseram se atualizar

REMIPE- Revista de Micro e Pequenas Empresas e Empreendedorismo da Fatec Osasco V. 2, `o2, jul.-dez. 2016. 
através de feiras , 12,20\% através de seminários e palestras e 31,71\% informaram não participa de nenhum tipo de atividade de reciclagem ou atualização. É importante observar que, para esta questão, alguns respondentes assinalaram mais de uma alternativa, o que justifica um resultado superior a $100 \%$.

Schmidt (2002) comenta que, em geral, as grandes empresas são divididas em departamentos que prestam constas aos gestores das mesmas, de forma auxiliá-los no planejamento e tomada de decisão. Das empresas pesquisadas, apenas 53,66\% possuem divisão de departamentos para controle das atividades diárias.

Conforme Garcia (2007), as principais funções que a controladoria possui são planejamento, execução e controle, tais funções, são suporte à diretoria para tomada de decisão, revisão e implementação de processos de controle. Embora a maioria dos pesquisados tenha afirmado que possuem divisão departamental para controle das atividades diárias, apenas 31,71\% afirmaram formalizar esse controle em papel, 14,63\% utilizam-se de um software, $19,51 \%$ fazem uso de planilhas e $36,59 \%$ de outros recursos.

Em relação ao controle de impostos, $73,17 \%$ fazem seus controles externamente, através de escritórios contábeis e apenas $26,83 \%$ possuem controles internos. De acordo com Murakawa et al. (2010), o planejamento nas empresas é uma ferramenta de gestão que, além de ser necessária para tomada de decisão, evita o mau uso dos recursos, resultando na observação da relevância do orçamento empresarial na otimização dos resultados. Wilson, Roehl-Anderson e Bragg (2000) apud Scarpin (2006) complementam que o planejamento estabelece a manutenção de curto e longo prazo em virtude das metas e objetivos da empresa. A pesquisa mostrou que $46,34 \%$ fazem planejamento semestral, $34,15 \%$ mensalmente, 7,32 anualmente e apenas $12,20 \%$ não fazem nenhum planejamento orçamentário.

Geralmente parte do Lucro do período é reinvestida na empresa para a expansão no mercado, das empresas pesquisadas apenas 53,66\% reinveste seus recursos, 20 a $40 \%$ dos seus lucros, em segundo com $34,15 \%$, em terceiro, $4,88 \%$ e apenas $7,32 \%$ não reinveste nada.

Ao serem questionadas sobre a perspectiva de crescimento do setor, $40 \%$ a $50 \%$ das empresas responderam que há uma perspectiva de crescimento de $48,78 \%$ no ano, e $10 \%$ a

REMIPE- Revista de Micro e Pequenas Empresas e Empreendedorismo da Fatec Osasco V. 2, `o2, jul.-dez. 2016. 
$20 \%$ afirmaram que o crescimento será de 21,95\%. A Federação das Indústrias do Estado de São Paulo - FIESP (2013), realizou um estudo sobre a indústria têxtil e de confecção onde constatou que este seguimento representa uma projeção de crescimento de $3 \%$ do PIB em 2014.

De acordo com Garcia (2007), as demonstrações contábeis e econômicas possibilitam formar cenários econômicos para projetar investimentos futuros, tais como planejamento, controle, relatórios e contabilidade, essas são etapas relevantes para tomada de decisão. Sobre esta afirmação, 53,66\% das empresas alegam concordar com essa ideia, e $21,95 \%$ responderam que a contabilidade, isoladamente, possui maior relevância na tomada de decisão.

Quando questionado sobre qual a maior dificuldade encontrada no setor de confecção, 9,76\% relataram que são o aumento de impostos, 14,63\% responderam a falta de mão de obra qualificada, 26,83\% informaram concorrência desleal, 21,95\% rentabilidade baixa e 29,27\% afirmaram que são todas as anteriores. O Instituto Brasileiro de Planejamento Tributário - IBPT (2013) comenta que, apesar das desonerações tributárias concedidas pelo governo e da economia mais fraca em 2013, a carga tributária brasileira deve encerrar 2013 em alta e subir com ainda mais força em 2014.

\section{CONCLUSÕES}

Os dados foram coletados no período do dia 28 de abril a 06 de maio de 2014 , distribuídos diretamente por meio de questionário com treze perguntas fechadas aplicados na região do Brás em São Paulo. A pesquisa teve como objetivo identificar qual é a percepção dos gestores sobre a controladoria e o que eles consideram como pontos fortes e fracos.

Sobre a percepção dos gestores, 53,66\% dividem sua empresa em setores e estes buscam conhecimentos em eventos para atualizar os seus conhecimentos. Todos possuem uma forma de controlar sua produção, tal que a maior parte controla a produção por meio da ficha em papel e a minoria utiliza-se de software personalizados de controle. Em caráter

REMIPE- Revista de Micro e Pequenas Empresas e Empreendedorismo da Fatec Osasco V. 2, N², jul.-dez. 2016. 
relevante, $87 \%$ dos gestores compreendem a importância do planejamento. Quanto à importância de reinvestimento, 53\% dos gestores reinvestem até $40 \%$ do seu lucro na empresa.

Os principais pontos fortes em comum são a faixa etária dos gestores, entre 30 a 40 anos, o controle da produção por departamentos, a existência de planejamento, todos possuem perspectiva de crescimento no ano e concordam que o planejamento, controle, relatórios e contabilidade são primordiais para seus negócios. Sobre as dificuldades do segmento, as principais são os impostos, falta de mão de obra, concorrência desleal e a baixa rentabilidade.

Quanto aos pontos fracos, a maioria não possui curso superior, $34,15 \%$ não participam de nenhum evento na área como forma de atualização, a maioria não possui um sistema de controle adequado de produção e controlam seus impostos apenas externamente.

De forma geral, os resultados demonstraram que os gestores, concordaram com as principais funções da controladoria para a empresa, mas apresentaram alguns contrapontos que se destacam: Todos almejam crescimento, contudo reinvestem pouco; todos possuem uma boa perspectiva de crescimento no ano, mas tem pouca mão de obra qualificada; concordaram com a importância de se ter um sistema de controle, porém 73,17\% controlam seus impostos apenas, externa por meio de consultoria contábil e apenas 14,63\% utilizam software de controle de produção e desenvolvimento.

Como estudos futuros, sugere-se aprofundar na análise econômica financeira das empresas do setor, ou ainda identificar fatores que contribuam para o desenvolvimento da atividade, tal qual o grau de satisfação dos funcionários desse setor. Outra possibilidade seria traçar uma comparação dos resultados encontrados com outras regiões do estado e do país em que se constata desenvolvimento similar do setor.

\section{REFERÊNCIAS}

BRASIL. LEI COMPLEMENTAR $\mathrm{N}^{\circ}$ 123, DE 14 DEZEMBRO DE 2006. Regulamenta o inciso I e II do art. $2^{\circ}$, DA definição de microempresa de pequeno porte. Disponível

REMIPE- Revista de Micro e Pequenas Empresas e Empreendedorismo da Fatec Osasco V. 2, `o2, jul.-dez. 2016. 
em:<http://www.receita.fazenda.gov.br/Legislacao/LeisComplementares/2006/leicp123.htm> . Acesso em 02 de Outubro de 2013

BEUREN, SCHLINDWEIN E PASQUAL. Abordagem da Controladoria em trabalhos Publicados no ENANPAD e No Congresso USP de Controladoria e Contabilidade de 2001a 2006. Revista Contabilidade e Finanças USP, V. 18, n 45, p.23 set/dez.2007.

BORNIELLI, Márcio Luiz. Estrutura básica de controladoria: Sistematização à luz da teoria e da práxis, 2006. Tese (Doutorado em Controladoria e Contabilidade) - Curso de Pós Graduação em Contabilidade, Faculdade de Economia, Administração e Contabilidade da Universidade de São Paulo.

CATELLI, Armando. Controladoria uma Abordagem da Gestão Econômica GECON. 2. ed. São Paulo: Editora Atlas, 2001.

CASAGRANDE, Luiz Fernandes, Pinto, Dâmaris Martins. Procedimentos de controladoria aplicados na empresa auto som Galeazzi, 2010. Curso de Ciências Contábeis da Universidade Tecnológica Federal do Paraná, Campus Pato Branco/PR.

CINTRA, Y. C. A interação da sustentabilidade às práticas de controle gerencial das empresas do Brasil. Um estudo de caso. 2011. 61. Dissertação de doutorado - Universidade de São Paulo, USP, 2011. FREZATTI, Fábio; Rocha, Welington;

COSTA, Ana Cristina Rodrigues da; Rocha, Érico Rial Pinto da. Panorama da cadeia produtiva têxtil e de confecções e a questão da novação. BANCO NACIONAL DO DESENVOLVIMENTO - BNDS - Caracterização do cenário macroeconômico. 29 de Janeiro de 2009. Disponível em: $\leq$ http://www.bndes.gov.br/SiteBNDES/bndes/bndes_pt/Institucional/Publicacoes/Consulta_Ex pressa/Setor/Complexo_Textil/200903 05.html>. Acesso em: 10 de Setembro 2013.

CRUZ, Bleise Rafael da. A Prática da Controladoria nos maiores bancos que operam no Brasil á luz de uma estrutura conceitual básica de controladoria, 2009. Tese (Mestre em Ciências Contábeis) - Curso de Pós Graduação em Contabilidade, Faculdade de Economia, Administração e Contabilidade da Universidade de São Paulo.

EMPRESA DE PESQUISA ENERGÉTICA - EPE, BANCO NACIONAL DO DESENVOLVIMENTO - BNDS - Caracterização do cenário macroeconômico. 11 de Dezembro de 2011. Disponível em: <http://www.epe.gov.br/mercado/Documents/S\%C3\%A9rie\%20Estudos\%20de\%20Energia/2 0120104_2.pdf>. Acesso em: 10 de Setembro 2013.

FEDERAÇÃO DAS INDÚSTRIAS DO ESTADO DE SÃO PAULO - FIESP. Atividade e emprego na indústria devem reverter quadro negativo no próximo ano, segundo estimativas da entidade. 18 de Dezembro de 2012. Disponível em: 
$<$ http://www.fiesp.com.br/noticias/pib-do-brasil-e-da-industria-deve-crescer-3-em-2013projeta-fiesp/>. Acesso em: 10 de Setembro 2013.

GARCIA, Alexandre Sanches. Introdução à controladoria instrumentos básica de controle de gestão das empresas. 1. Ed. São Paulo, Atlas, 2010.

LUCIO, PILAR BAPTISTA; COLLADO, CARLOS FERNÁNDEZ; SAMPIERI, ROBERTO HERNANDES. Metodologia de Pesquisa. 3 ed. São Paulo, McGraw - Hill, 2006.

MINISTÉRIO DE DESENVOLVIMENTO, INDÚSTRIA E COMERCIO EXTERIOR MIDC. Cadeia Produtiva Têxtil e de Confecções. Disponível em:

$\langle$ http://www.desenvolvimento.gov.br/sitio/interna/interna.php?area=2\&menu=3696 >>.

Acesso em: 10 de Setembro 2013

MURAKAWA NETO, Paulo Kioti et al. Análise dos Fatores Relevantes na Construção de Alianças Sociais: Um Estudo de Caso na Uniong - Sorocaba. VI Encontro de Estudos em Estrategia, Bento Gonçalves - RS 19 a 21 de Maio de 2013. Disponível em

:<http://www.anpad.org.br/diversos/trabalhos/3Es/3es_2013/2013_3Es266.pdf>

NASCIMENTO, Artur R. do; JUNQUEIRA, Emanuel. Controle Gerencial: Uma abordagem da contabilidade gerencial no contexto econômico, comportamental e sociológico. São Paulo: Atlas, 2009.

NASCIMENTO, Auster Moreira. Controladoria um Enfoque na Eficácia Organizacional. 1. Ed. São Paulo, Atlas, 2007.

PADOVEZE, CLOVIS LUIS. Controladoria Estratégica e Operacional. 2. ed. São Paulo: Cengage Learning, 2009

PEREIRA, Jose Matias. Manual de Metodologia da Pesquisa Científica. 2. ed. São Paulo: Atlas, 2010.

ROEHL-ANDERSON, JANICE M. and BRAGG, STEVEN Controllership: the work of the managerial accountant. New York: John Wiley\&Sons, Inc. 2004.

SCARPIN, Jorge Eduardo. Estudo dos fatores condicionantes do índice de desenvolvimento Humano nos Municípios do Estado do Paraná: Instrumentos de Controladoria para tomada de Decisões na Gestão Governamental. Um estudo de caso. 2006. Dissertação de doutorado - Universidade de São Paulo, USP, 2006.

SEVERINO, Antônio Joaquim. Metodologia do Trabalho Científico. $23^{\circ}$ ed. Cortez Editora, 2007.

SILVA, Edna Lucia da; MENEZES, Estera Muszkat. Metodologia da pesquisa e elaboração de dissertação. 4. ed. Florianópolis: UFSC, 2005. Disponível 
em:<http://www.portaldeconhecimentos.org.br/index.php/por/content/view/full/10232>.Acess o em: 18 jan. 2014.

SIQUEIRA, Jose Ricardo Maia; SOLTELINHO,Wagner- O Profissional de Controladoria no Mercado Brasileiro - Do Surgimento da Profissão aos Dias Atuais. Revista Contabilidade \& Finanças FIPECAFI - FEA - USP, São Paulo, FIPECAF. Dezembro de 2011. Disponível em: < http://www.scielo.br/pdf/rcf/v12n27/v12n27a05.pdf>. Acesso em: 10 de Setembro 2013.

VARELA, P. S. Financiamento e controladoria dos municípios paulistas no setor saúde: Uma avaliação de eficiência. Um estudo de caso. 2008, 28. Dissertação de doutorado Universidade de São Paulo - USP, São Paulo 2008. 